Original Article

\title{
MAINTENANCE OF CONSENT PAPER IN DAILY DENTAL PRACTICES
}

\author{
Nabhira Aftabi Binte Islam ${ }^{1}$, Sharika Shahrin', Md. Hamdullah ${ }^{3}$
}

\begin{abstract}
Background: To assess maintenance of consent paper in daily dental practices.

Methods: It was a cross-sectional study. To assess maintenance of consent paper in daily dental practice at the chambers of the dentist. Data were collected through face to face interview. Dental chambers were selected by simple random sampling technique and respondents were selected purposively in Mymensingh sadar. 50 chambers and 70 dental surgeons were interviewed. Study period was January to March, 2019.

Results: In respect of distribution of the chamber owners by sex, female owners comprised $16 \%$ and $84 \%$ was male owners. By educational background of chamber owners, $40 \%$ owners had no B.D.S degree. It was found that $16 \%$ dental chambers had two dental surgeons and $84 \%$ dental chambers had one dental surgeon. Of all, $92.90 \%$ dental surgeons had knowledge about consent paper. The study showed that $80 \%$ dental surgeon sometimes, $7.1 \%$ dental surgeon always maintained consent paper in daily practice. Among the dental surgeons, $44.3 \%$ sometimes faced problem for taking consent paper in daily practice. Among all, $71.4 \%$ maintained verbal consent, $7.1 \%$ written and $21.4 \%$ maintained implied consent. Of all, $94.3 \%$ dental surgeons maintained written consent paper only for costly treatment and specialized cases while $18.6 \%$ thought that it was not important and $40 \%$ thought that time consuming and $34.3 \%$ thought that patients were not interested. It was also found that $42 \%$ ancillary of the dental chambers had diploma degree and $58 \%$ had no degree.
\end{abstract}

Conclusion: It is a general legal and ethical principle that one must get valid consent because it is the patients' rights before starting treatment or physical investigation.

JOPSOM 2021; 40(1):22-25

https://doi.org/10.3329/jopsom.v40i1.56687

Keywords: Consent paper, Dental chamber, Implied consent, Verbal consent, Written consent.

1. Assistant professor, B.D.S (D.U), MPH (NIPSOM), Dental Public Health Department, Marks Medical College (Dental Unit)

2. Assistant Professor and Head of the Department of Pediatric Dentistry Gonoshasthaya Samaj Vittik Medical College (Dental Unit)

3. Medical Officer, Department of Community Medicine, NIPSOM, Dhaka

Correspondence: Dr. Nabhira Aftabi Binte Islam,e-mail: nabhira14@yahoo.com.

\section{INTRODUCTION}

Consent occurs when one person voluntarily agrees to the proposal or desires of another. ${ }^{1}$ It is the legal issue that protects every patient's right not to be touched or in any way treated without the patient's authorization. The issue assumes that it is a right of mentally competent adults and of sound mind to determine what should be done with their body and the surgeon who performs operation without patient's consent commits assault for which the surgeon is liable in damages. ${ }^{2}$ Before providing care or treatment to a patient, the dentist must obtain the individual's free and informed consent. This requirement is based on two principles: personal inviolability and free will.

Types of consent include implied consent, expressed consent. Expressed consent is again two types - a. verbal consent and another is b. written consent. Consent as understood in specific contexts may differ from its everyday meaning. ${ }^{3}$

Implied consent is a form of consent which is not expressly granted by a person, but rather inferred from a person's actions and the facts and circumstances of a particular situation (or in some cases, by a person's 
silence or inaction). Rowe described implied consent as: 'by being in the chair at the dental surgery with mouths open a patient implies that they are there for dental treatment' and continued 'in the past a dentist would undertake treatment as he or she saw fit, which the patient would accept without argument' ${ }^{4}$. Expressed consent is clearly and unmistakably stated, rather than implied. It may be given in writing, by speech (orally), or non-verbally.

\section{MATERIALS AND METHODS}

A cross-sectional study was conducted to assess maintenance of consent paper in dental practice at dentist chambers in Mymensingh sadar. Data were collected through face to face interview. Study period was $13^{\text {th }}$ January to $14^{\text {th }}$ March, 2019. 50 chambers were visited and 70 dental surgeons were interviewed. Verbal Consent was taken from the respondents. Dental chambers were selected by simple random sampling technique and respondents were selected purposively. A semi-structural questionnaire was developing in English. Data were presented by simple frequency table.

\section{When Consent is not Valid ${ }^{5,6}$}

1. Given by a person under 18 years of age.

2. Given by a person of unsound mind.

3. Given under fear, fraud or misrepresentation of facts.

4. Person who is ignorant of the implications of the consent.

5. Procedure for illegal surgical procedure.

6. Patient who is unaware of harmful consequences of treatment

\section{RESULTS}

Distribution of the Chamber owner according to sex summarized in (table-1) and female owner is $16 \%$ and $84 \%$ is male owners. Educational background of chamber owner is alarming. $40 \%$ owner has no B.D.S degree. $16 \%$ dental chambers have two dental surgeons and $84 \%$ dental chambers has one dental surgeon.

Table 1: Condition of dental chambers and its owners $(n=50)$

\begin{tabular}{|l|l|l|}
\hline \multicolumn{3}{|l|}{ Distribution of the Chamber owner according to sex } \\
\hline \multicolumn{1}{|c|}{ Attributes } & Frequency & \\
\hline Male & 42 & 84 \\
\hline Female & 8 & 16 \\
\hline Total & \multicolumn{1}{|c|}{50} & 100 \\
\hline Educational background of the chamber owner \\
\hline Non B.D.S & 20 & 40 \\
\hline B.D.S and above & 30 & 60 \\
\hline Total & 50 & 100 \\
\hline How many doctors work in a chamber & \multicolumn{2}{|}{} \\
\hline One & 42 & 84 \\
\hline Two & 8 & 16 \\
\hline Total & 50 & 100 \\
\hline Degree of the ancillary on chamber & & \\
\hline Non & 29 & 58 \\
\hline Diploma & 21 & 42 \\
\hline Total & 50 & 100 \\
\hline
\end{tabular}

92.90\% dental surgeon has knowledge about consent paper (Fig: 1). 
Fig: 1 Knowledge about consent

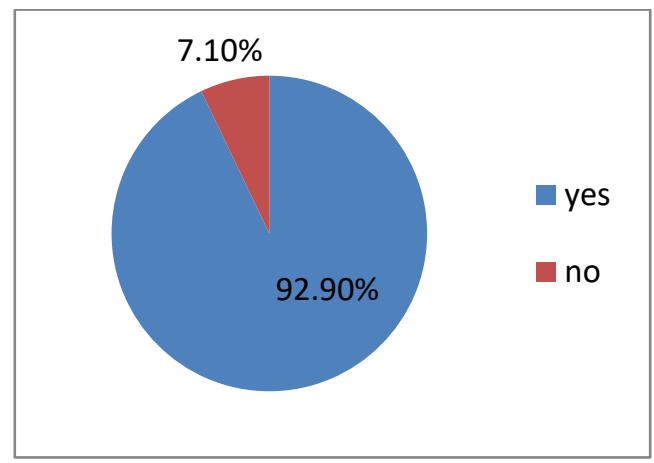

$80 \%$ dental surgeon sometimes, $7.1 \%$ dental surgeon always maintain consent paper in daily practice (table2). $44.3 \%$ dental surgeon sometimes faced problem for lacking consent paper in daily practice. $71.4 \%$ dental surgeon maintains verbal consent, $7.1 \%$ written and $21.4 \%$ maintain implied consent. 94. 3\% dental surgeon maintains written consent paper only for costly treatment and specialized cases. $18.6 \%$ dental surgeon thought that it's not important and 40\% thought that time consuming and $34.3 \%$ thought that Patients are not interested.

Table 2: Maintenance of consent in daily dental practices $(n=70)$.

\begin{tabular}{|c|c|c|}
\hline \multicolumn{3}{|c|}{ Consents Maintain in daily dental practice } \\
\hline Attributes & & \\
\hline & Frequency & Percent \\
\hline Yes & 5 & 7.1 \\
\hline No & 9 & 12.9 \\
\hline Sometimes & 56 & 80 \\
\hline Total & 70 & 100 \\
\hline \multicolumn{3}{|c|}{ Problem for lacking consent paper in daily practice } \\
\hline No & 29 & 41.4 \\
\hline Yes & 6 & 8.6 \\
\hline Sometimes & 31 & 44.3 \\
\hline Missing & 4 & 5.7 \\
\hline Total & 70 & 100 \\
\hline \multicolumn{3}{|l|}{ Type of consent normally maintained } \\
\hline Verbal & 50 & 71.4 \\
\hline Written & 5 & 7.1 \\
\hline Implied & 15 & 21.4 \\
\hline Total & 70 & 100 \\
\hline \multicolumn{3}{|c|}{ Types of cases maintained for written consent } \\
\hline Costly treatment and Specialized cases & 66 & 94.3 \\
\hline All cases & 4 & 5.7 \\
\hline Total & 70 & 100 \\
\hline \multicolumn{3}{|c|}{ Reasons for not using consent in daily practice } \\
\hline Not important & 13 & 18.6 \\
\hline Time consuming & 28 & 40 \\
\hline Patients are not interested & 24 & 34.3 \\
\hline Missing & 5 & 7.1 \\
\hline Total & 70 & 100 \\
\hline
\end{tabular}




\section{DISCUSSION}

Distribution of the Chamber owner according to sex, female owner is $16 \%$ and $84 \%$ is male owners. Educational background of chamber owner is alarming. $40 \%$ owner has no B.D.S degree. $16 \%$ dental chambers have two dental surgeons and $84 \%$ dental chambers has one dental surgeon. $92.90 \%$ dental surgeon has knowledge about consent paper another study showed that

94.3\% dental professionals have knowledge about consent paper ${ }^{7}$. $80 \%$ dental surgeon sometimes, $7.1 \%$ dental surgeon always maintains consent paper in daily practice. Another result also showed that $80 \%$ of dental surgeon obtained it in practice ${ }^{8}$, which result is more similar of this paper. $44.3 \%$ dental surgeon sometimes faced problem for lacking consent paper in daily practice another research paper of The Corbin v. Dupont ${ }^{9}$ case is a good example of this. $71.4 \%$ dental surgeon maintains verbal consent, $7.1 \%$ written and 21 other hands one study showed that

$11.2 \%$ obtained oral form of Informed Consent from their patients provide oral and written form in all cases $^{10} .4 \%$ maintain implied consent. $94.3 \%$ dental surgeon maintains written consent paper only for costly treatment and specialized cases. $18.6 \%$ dental surgeon thought that it's not important and $40 \%$ thought that time consuming and $34.3 \%$ thought that Patients are not interested. $42 \%$ ancillary of the dental chambers has diploma degree and $58 \%$ has none of any degree they have.

Subject to the small sample size, then study findings may not represent the true picture of the country. Before providing care or treatment to a patient, the dentist must obtain the individual's free and informed consent. This requirement is based on two principles: personal inviolability and free will ${ }^{11}$. It is self-evident, therefore, that every practitioner, therapist, and hygienist needs not only a thorough understanding of the principles of consent, but also an awareness of how to apply these principles in the wide variety of circumstances that can arise in the practice of dentistry $^{12}$.

\section{CONCLUSION}

The study recommends awareness programs and workshops for developing knowledge of both patient and doctor about importance of consent. The study also suggests execution of relevant laws in the country.

\section{REFERENCES}

1. "Home : Oxford English Dictionary". www.oed.com. Retrieved 2016-03-24.
2. Cannavina CD, Cannavina G, Walsh TF (2000)

Effects of evidence-based treatment and consent on professional autonomy. Br Dent J 188: 302306.

3. International technical guidance on sexuality education: An evidence-informed approach (PDF). Paris: UNESCO. 2018. p. 56. ISBN 97892-3-100259-5.

4. Rowe AH (1994) Consent. Dent Update 21: 188-190.

5. Consumer Protection Act (2007) In: Hiremath SS (edr.), Textbook of Preventive and Community Dentistry. India: Elsevier, 298-305.

6. Indian Penal Code 1860, Sections 87-92.

7. Knowledge and Attitude Toward Informed Consent in Medical and Dental Practitioners, of Bhopal City, India. Anshika Khare, Vrinda Saxena, Manish Jain, Vijayta Sharva, Prakash Singh, Ashwini Dayma Department of Public Health Dentistry, People's Dental Academy, Bhopal, Madhya Pradesh, India.

8. Avramova N, Yaneva K. Patients' informed consent in dental practice in Bulgaria. Oral Health Dent Manag. 2011; 10:80-7. [Google Scholar]

9. Corbin c. Dupont, [1994] A.Q. no 1248, \#20005-000828-926 (C.S.); [1997] A.Q. no 3726, \#200-09-000350-949 (C.A.).

10. The Personalized Consent Form: An Optional, but Useful Tool. Cyndie Dubé-Baril, DMD, LLM. 2004; 70(2):89-92.

11. The Practice of Informed Consent among Dental Practitioner of NCR. Sanchit

12. Pradhan, Sumanth Prasad, Suchi Khurana, Chinmaya BR, Shourya Tandon.

13. Consent [monograph on the internet] Edinburgh: 2009. [Last cited on 2013 May 20]. Dental Protection. Available from: http://www.dentalprotection.org . [Google Scholar] 